\title{
Influence of inherent strain on the curie temperature of rare earth ion-doped bismuth vanadate
}

\author{
K SOORYANARAYANA, T N GURU ROW*, R SOMASHEKAR ${ }^{\ddagger}$ and K B R VARMA ${ }^{\dagger}$ \\ Solid State and Structural Chemistry Unit, ${ }^{\dagger}$ Materials Research Centre, Indian Institute of Science, \\ Bangalore 560012 , India \\ ${ }^{\ddagger}$ Department of Studies in Physics, University of Mysore, Mysore 570006 , India
}

MS received 8 May 1998; revised 8 September 1998

\begin{abstract}
X$-ray line broadening is found to be an effective parameter to estimate the strain associated with rare earth ion $\left(\mathrm{Gd}^{3+}\right)$-doped polycrystalline bismuth vanadate $\left(\mathrm{Bi}_{2} \mathrm{VO}_{5.5}\right)$. The strain increases with increasing $\mathrm{Gd}^{3+}$ concentration. It is anisotropic and found to be maximum in (111) plane. The Curie temperature which is known to decrease with increase in the rare earth ion concentration in these compounds is correlated with increase in strain.
\end{abstract}

Keywords. $\mathbf{G d}^{3+}$ doped bismuth vanadate; strain analysis; curie temperature.

\section{Introduction}

The effect of rare earth ion doping on the ferroelectric properties of Aurivillius family of oxides has been reported in literature (Wolfe and Newnham 1969; Armstrong and Newnham 1972; Shimaju et al 1980; Watanabe 1980; Watanabe et al 1980). The Curie temperature $\left(T_{\mathrm{v}}\right)$ of these compounds has been reported to be strongly dependent on the concentration and the radius of the rare earth ion dopant. Recently influence of rare earth ion doping on the structural, dielectric, and ferroelectric properties of vanadium analogue of the $n=1$ member of the Aurivillius family of oxides $\left(\mathrm{Bi}_{2} \mathrm{VO}_{5.5}\right)$ was reported by Prasad et al (1995). Their investigations confirm the decrease in $T_{c}$ with increase in rare earth ion concentration and its size. This decrease in $T_{c}$ was attributed to the decrease in orthorhombic distortion ( $b / a$ ratio). We have made an attempt in the present investigation to strengthen these observations quantitatively as the strain associated with pure as well as $\mathrm{Gd}^{3+}$-doped bismuth vanadate.

\section{Experimental}

The polycrystalline powders $(\sim 10 \mu \mathrm{m}$ grain size $)$ of $\mathrm{Bi}_{2-x} \mathrm{Gd}_{x} V_{55}(0 \leq x \leq 0 \cdot 1)$ used for the present investigations were synthesized by the conventional solid-state synthesis route (6). The mixture of reactor grade $\mathrm{Bi}_{2} \mathrm{O}_{3}$, $\mathrm{V}_{2} \mathrm{O}_{5}$ and $\mathrm{Gd}_{2} \mathrm{O}_{3}$ was heated initially up to $770 \mathrm{~K}$ and finally at $1150 \mathrm{~K}$ for $48 \mathrm{~h}$ in air with intermediate grinding. The rare earth oxide $\left(\mathrm{Gd}_{2} \mathrm{O}_{3}\right)$ was heated at

*Author for correspondence
$870 \mathrm{~K}$ for about $4 \mathrm{~h}$ before weighing. The compositional analyses of all the samples under investigation were carried out using a Cambridge S360 scanning electron microscope associated with a LINKS AN 10000 EDX facility. These studies confirm the stoichiometry and the presence of $\mathrm{Gd}^{3+}$ in the synthesized samples.

High-resolution powder $\mathrm{X}$-ray diffraction patterns were collected on a STOE/STADI-P powder diffractometer with Bragg-Brentano geometry (fine focus setting) with germanium monochromated $\mathrm{CuK} \alpha 1 \quad(\lambda=1.54056 \AA)$ radiation in $2 \theta$ range $5-80^{\circ}$ at intervals of $0.02^{\circ}$ using a linear position detector in the transmission mode. These diffraction patterns were indexed, and the cell parameters were refined using programs INDEX (based on trial and error method using procedure of permutating indices from a few basal reflections) and REFINE (refinement of lattice constants) of STOE/STADI-P diffraction system.

\section{Theoretical background}

The X-ray profile broadening is known to be mainly due to (i) size broadening, caused by a finite size of regions in the specimens diffracting incoherently with respect to each other, (ii) strain broadening due to varying displacements of the atom with respect to their reference positions, and (iii) instrumental broadening. Normally specimen-size broadening is negligibly small and it will be ignored. The major contribution to the broadening of a X-ray reflection profile is from the number of unit cells $(N)$ counted in a direction perpendicular to the Bragg plane and the lattice strain present in the material along this direction. 
A generally applicable one-dimensional model based on distortion of the lattice (Somashekar and Somashekarappa 1997), has been used to obtain the average microstructural parameters like crystal size and strain along different directions of the lattice employing individual $(h k l)$ reflections. The corrected experimental X-ray profile was matched with the simulated profile using the equations:

$$
I(s)=I_{N-1}(s)+I_{N}^{\prime}(s),
$$

where $I_{N}^{\prime}(s)$ is the modified intensity for the probability peak centred at $D\left(=N d_{h k}\right)$. It has been shown that (Mark Silver 1988)

$$
\begin{aligned}
I_{N}^{\prime}(s)= & \left(2 a_{N} / D(\pi)^{1 / 2}\right)(\exp (i d s))\left[1-a_{N} s\left\{D\left(a_{N} s\right)\right.\right. \\
& \left.\left.+i(\pi)^{1 / 2} \exp \left(-a_{N^{2}} s^{2}\right)\right\}\right]
\end{aligned}
$$

with $a_{\hat{N}}=N \omega^{2} / 2$ and $D\left(a_{N} s\right)$ is the Dawson's integral or error function. $I_{N}^{\prime}(s)$ is modified intensity for the probability peak centred at $D$.

\section{Results and discussion}

The high resolution powder $\mathrm{X}$-ray diffraction patterns recorded for $\mathrm{Bi}_{2-x} \mathrm{Gd}_{x} \mathrm{VO}_{5.5}(x=0.0,0.05$ and 0.1$)$ are shown in figure 1 . The $\mathrm{X}$-ray reflections marked by closed circles in figures $1 b$ and $c$ are identified with $\mathrm{GdVO}_{4}$ phase. These reflections are not considered for the strain calculations. The diffraction profiles were corrected for instrument broadening by calibrating NBS (National Bureau of Standards, Washington DC, USA) silicon sample. Since the contribution to the profile broadening is significant when the particle size is less than $0.2 \mu \mathrm{m}$ (West 1984), it can be ignored in the present case since the grain size of the polycrystalline samples was about $10 \mu \mathrm{m}$. The experimental profile between $s_{0}$ and $s_{0}+s_{0} / 2$ (or $s_{0}$ and $s_{0}+B / s d$, if there is truncation of the profile $B<1$ ) is matched with corresponding simulated order of reflection between $s_{0}$ and $s_{0}+s_{0} / 2$ (or $s_{0}$ and $s_{0}+B / 2 d$ ) for various values of $N$ and $g$ to minimize the difference between calculated and experimental normalized intensity values. SIMPLEX, a multidimensional algorithm (Press et al 1986) is used for minimization. It has been noticed that the parameter

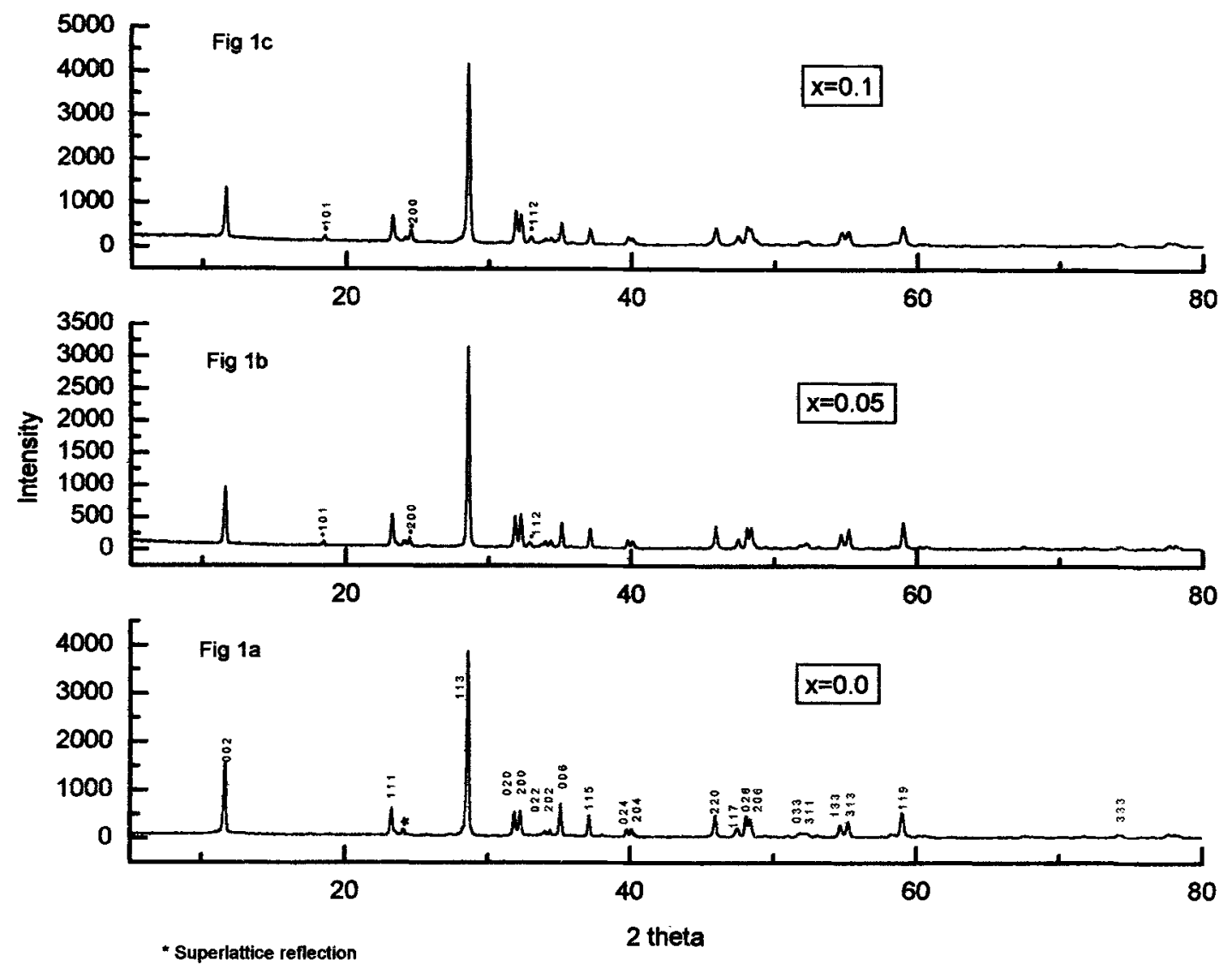

Figure 1. Powder X-ray diffraction patterns of $\mathrm{Bi}_{2-x} \mathrm{Gd}_{x} \mathrm{VO}_{5.5}(x=0.0,0.05$ and 0.01). 
Table 1. Variation of strain as a function of $\mathrm{Gd}^{3+}$ concentration in $\mathrm{Bi}_{2} \mathrm{VO}_{5 \cdot 5}$.

\begin{tabular}{|c|c|c|c|c|c|c|}
\hline \multirow[b]{2}{*}{ Reflection } & \multicolumn{2}{|c|}{$\mathrm{Bi}_{2-x} \mathrm{Gd}_{x} \mathrm{VO}_{5.5}(x=0)$} & \multicolumn{2}{|c|}{$\mathrm{Bi}_{2-x} \mathrm{Gd}_{x} \mathrm{VO}_{5.5}(x=0.05)$} & \multicolumn{2}{|c|}{$\mathrm{Bi}_{2-x} \mathrm{Gd}_{x} \mathrm{VO}_{5.5}(x=0.01)$} \\
\hline & $N$ & $g$ & $N$ & $g$ & $N$ & $g$ \\
\hline 002 & $45 \cdot 48$ & $4 \cdot 31(1)$ & 37.508 & $2 \cdot 174(5)$ & $19 \cdot 273$ & $2 \cdot 066(1)$ \\
\hline 200 & 63.78 & $1.630(7)$ & $73 \cdot 16$ & $1 \cdot 16(4)$ & 57.67 & $1.71(7)$ \\
\hline 006 & $60 \cdot 06$ & $0.03(1)$ & 63.86 & $1 \cdot 52(2)$ & $50 \cdot 375$ & $0.50(1)$ \\
\hline 020 & 53.66 & $0 \cdot 01(3)$ & $69 \cdot 65$ & $0 \cdot 26(6)$ & $70 \cdot 323$ & $0 \cdot 323(6)$ \\
\hline 220 & $82 \cdot 89$ & $0.83(8)$ & $64 \cdot 07$ & $1 \cdot 19(1)$ & $61 \cdot 598$ & $1 \cdot 323(5)$ \\
\hline 111 & 99.86 & $3 \cdot 46(4)$ & 56.591 & $2 \cdot 646(5)$ & 47.634 & $2 \cdot 82(7)$ \\
\hline 115 & $68 \cdot 27$ & $0.92(1)$ & $78 \cdot 39$ & $1 \cdot 04(6)$ & 50.437 & $0.73(1)$ \\
\hline 113 & 69.325 & $1.72(3)$ & $74 \cdot 22$ & $1.59(4)$ & $48 \cdot 784$ & $1.05(6)$ \\
\hline 117 & 68.45 & $0.31(2)$ & 81.454 & $0.235(7)$ & 52.543 & $0.01(2)$ \\
\hline
\end{tabular}

Table 2. A comparison of strain in $\mathrm{Bi}_{2-x} \mathrm{Gd}_{x} \mathrm{VO}_{5.5}(x=0.0,0.05$ and 0.1$)$ along with its $T_{\mathrm{c}}$ (Prasad et al 1995).

\begin{tabular}{|c|c|c|c|c|}
\hline Reflection & $N$ & $\stackrel{g}{(x=0)}$ & $(x=\stackrel{g}{0.05})^{*}$ & $\begin{array}{c}g \\
(x=\stackrel{0}{0} \cdot 1)^{*}\end{array}$ \\
\hline 220 & 82.89 & 0.83 & 1.539 & 1.780 \\
\hline $\begin{array}{lll}1 & 1 & 1\end{array}$ & $99 \cdot 86$ & 3.46 & 4.667 & 5.912 \\
\hline$T_{c}($ in $\mathrm{K})$ & & 725 & 720 & 709 \\
\hline
\end{tabular}

* Strain values are calculated with respect to the $N$ value of the pure bismuth vanadate $(x=0)$.

defining the lattice disorder $(g)$ affects the Gaussian shape of the profile whereas the number of sub-units counted in a direction perpendicular to the Bragg plane $(N)$ affects the Lorentzian shape of the profile. In these refinements, equal weightage has been given to both Gaussian and Lorentzian shapes of the profile. Table 1 lists the values of $N$ (number of unit cells counted in a direction perpendicular to the Bragg plane), $g$ (the lattice strain/disorder) obtained for all the reflections in different samples.

Two representative reflections 220 and 111 along with their $N$ and $g$ values normalized to the $N$ value of the pure compound are listed in table 2. The data on the curie temperature $\left(T_{\mathrm{c}}\right)$ of $\mathrm{Gd}^{3+}$-doped $\mathrm{Bi}_{2} \mathrm{VO}_{5.5}$ ceramics (as reported by Prasad et al (1995)) are also included in this table to indicate the behaviour with increasing concentration of these ions. It is evident that $T_{\mathrm{c}}$ decreases with increasing $\mathrm{Gd}^{3+}$ concentration. In pure (undoped) bismuth vanadate, we observe a lattice strain of $0.8 \%$ for reflection (220) (for distance of 83 times $d_{220}$ ), and for the same distance in doped materials it is $1.5 \%$ $(x=0.5)$ and $1.78 \%(x=0.1)$, respectively (table 2$)$, implying that the strain associated with the samples increase with increasing concentration of rare earth ion doping $\left(\mathrm{Gd}^{3+}\right)$. The effect of increase in strain with increasing $\mathrm{Gd}^{3+}$ ion concentration can be visualized as analogous to the pressure effects on $T_{c}$. The increase in pressure is known to lower the $T_{c}$ of ferroelectrics (Samara 1966).

\section{Conclusions}

We have demonstrated that X-ray line broadening could be effectively employed in estimating the strain associated with different planes in pure as well as rare earth ion-doped polycrystalline bismuth vanadate samples. The strain is found to increase with increase in $\mathrm{Gd}^{3+}$ concentration. The decrease in the Curie temperature as reported in the literature is attributed to the increasing strain with increasing $\mathrm{Gd}^{3+}$ content.

\section{Acknowledgements}

Authors thank Dr K V R Prasad for his help in synthesizing the materials used for the present study. KSN thanks the Council of Scientific and Industrial Research (CSIR), for the senior research fellowship and RS thanks the Jawaharlal Nehru Centre for Advanced Scientific Research, Bangalore for a visiting fellowship. We thank the Department of Science and Technology, New Delhi, for financial support.

\section{References}

Armstrong R A and Newnham R E 1972 Mater. Res. Bull. 7 1025

Mark Silver 1988 M.Sc. Thesis, UMIST, UK

Prasad K V R, Subbanna G N and Varma K B R 1995 Ferroelectrics 166223 
Press W, Flannery B P, Teukolsky S and Vetterling W T 1986 Numerical recipes (UK: Cambridge University Press) pp. 8385

Shimaju M, Tanaka J, Muramatsu K and Tsukioka M $1980 \mathrm{~J}$. Solid State Chem. 35402

Somashekar R and Somashekarappa H 1997 J. Appl. Cryst. 30 147

Samara G A 1966 Phys. Rev. 151378
Vainshtein B K 1996 Diffraction of X-rays by chain molecules (London and New York: Elsevier Publishing Co.)

West A R 1984 Solid state chemistry and its applications (New York: John Wiley \& Sons) p. 51

Wolfe R W and Newnham R E 1969 J. Electrochem. Soc. 116832

Watanabe A 1980 Mater. Res. Bull. 151473

Watanabe A, Inoue Z and Ohsaka T 1980 Mater. Res. Bull. 15 397 